\title{
Conceptual Urban Planning a Prerequisite for Physical Urban Planning
}

\author{
Hamidreza varesi ${ }^{1} \&$ Mahmoud Mahmoudzade $^{2}$ \\ ${ }^{1}$ Associated Professor of Geography and Urban Planning, University of Isfahan, Faculty of Geographic Planning \\ Science, Isfahan, Iran \\ ${ }^{2}$ Ph.D Candidate, University of Isfahan, Faculty of Geographic Planning Science, Isfahan, Iran
}

Correspondence: Hamidreza varesi, Associated Professor of Geography and Urban Planning, University of Isfahan, Faculty of Geographic Planning Science, Isfahan, Iran. E-mail: h.varesi@geo.ui.ac.ir; mahmahuk@yahoo.c.uk

Received: December 21, 2015

Accepted: January 5, $2016 \quad$ Online Published: January 31, 2016

doi:10.5539/mas.v10n3p95

URL: http://dx.doi.org/10.5539/mas.v10n3p95

\begin{abstract}
In the contemporary urban order the rational connection between the physique of the city and its non-physical elements is a major concern. Whatever happens in the existence of a city like the social, cultural, economic and political interactions are the inevitable realities through which the qualification and quantification nature of the city are determined. All occurrences in these realities, the constituent elements, are subject to the structural process which can be regulated as one of the social organization (non-physical) in urban settings, namely the social organization of the city, economic organization of the city and the political organization of the city. These organizations have the ranking in importance according to the city scale. The objective here is to identify these organizations and their contributions in conceptual urban planning. The adopted method here is descriptive-analytic. In a comparative comparison between the physical and non-physical needs of human regarding an urban setting reveals that the non-physical aspect has priority with high importance since its effect on the citizens' satisfaction is specific and direct.
\end{abstract}

Keywords: city, non-physical, urban planning, physical urban planning, human needs

\section{Introduction}

The city with both its physical and philosophical aspects constitute a habitat for human where the necessities of appropriate living conditions are to be provided; therefore, urban planning must with all its abilities meet the citizens' needs all fulfill their requirements. The physical and spiritual dimensions of the city both in a harmonized sense must provide the desirable living conditions for the citizens. The humanitarian needs in different societies fall in different ranges; hence, it can be deduced that these needs are proportional with respect to the citizens' talents, economic and social power "following a dynamic trend.

City can be defined as a surrounding the constituents of which are the identity and the affective worldview cultural and belief values of its citizens. This concept, in different locations with different natural surroundings and human behavior has been and is being influenced by historical and ideological evolutions.

Evolutions in modernity, in specific, have changed its process to a point that most of the symbolic elements of the old city have faded (Seyfian, 1999).

Human is influenced by his/her environ where he lives and this space shapes his/her identity and reveals his/her concealed identity and behavioral values specific to it his/her environ (Aminzade et al, 2002). How human behaves in urban setting depends on the level of the persons' knowledge about that setting. The concept of cognition is a mental process through which the sensible experiences gain significance, leading to the realization of the interaction among the issues and definition of subjects (Iravani and Khodapanah, 1992). When human tries to comprehend the interaction with and find his way in the urban space, in reality he wants to create a vivid coherent and consistent image of that space, where the constituent factors of this image are the non-physical ones (Bently, 2006). These can be considered as the most influential factors contributing to the urban elements, that is reflecting the ideas, the culture and the subsistence of its residents. In the formation of urban space, in its 
morphologic sense, the influencing regulations and values, the outcome of environmental, cultural, substantial/livelihood, socio-economic religious, ideological aspects cannot be ignored. Among these the influence of religious and world view are essential in shaping an urban setting.

According to Prof. Hofer "City in the crossing point of six concepts: economic structure (variety in activities), social structure (social diversification), physical structure, geographic structure, legal status and political life"(PapoliYazdi, 2008). According to Fakoohi (2004), city as the latest man-made habitat is a congestion site, for population with its complexities, socio-economic capitals, super visionary, political levers, physical and geographical space, symbolic aspects mostly exposed in a socio-cultural format. This makes the city a complicated reality where "The manner of multi dimensional crystallization develops the diversified epistemological approaches in epistemology.

Disregarding the non-physical structure of the cities is a serious threat to their residents. Promoting and highlighting the non-physical factors in planning in parallel with other appropriate approaches can assure enhance the city dynamism and increase citizen satisfaction with respect to endurance of urban identity. Most activities in the cities regarding socio-economic and political realms are organized and exhibited through the non-official organization. The urban governance systemize the guidance and direct these non-official organizations towards hard to fulfill policies and plans in a proper manner the outcome of which would be prosperity of the city and unification of these non-official organizations; hence, a positive effect on the physical aspect of the city.

The objective here is to identify the urban non-physical structure as one of the main principles on the path to reach the Utopia.

\section{Method}

The method adopted here is descriptive-analytic. To assess the records, themes, wholeness, definitions and the theoretical framework of this study comparison are made with corresponding literature.

The theoretical aspects defining some basic elements with respect to recognition of urban non-physical structure and the study conducted on it is of essence which would shade more light on the scientific terms regarding city and urban planning.

City is not an abstract and mental concept, but a specific type of organized social inhabitant in harmony with space. It is full of physical and non-physical, humanistic concepts and realities which provide for deep emotional connections (Pakzad, 2006). Human, with respect to its physiological and social features like: age, gender, social stratum, nationality, tribal affiliation, expertise etc. organizes the received information from environ and create an image of city in his mind, an image which will constitute the foundation for any action and reaction of self towards that environ (Torkashvand, 2013).

The concepts of city and citizen are combined; therefore, all societies thrive to develop healthy and enduring cities with more emphasis on the human factor than the physical aspects. It is obvious that if the citizens' needs and rights are not taken care of, the participation and cooperation principles, the most essential factors in materialization of Utopia will be doomed.

Whatever happens in the existence of a city like the social, cultural, economic and political interactions are the inevitable realities through which the qualification and quantification nature of the city are determined. All occurrences in these realities, the constituent elements, are subject to the structural process which can be regulated as one of the social organization (non-physical) in urban settings, namely the social organization of the city, economic organization of the city and the political organization of the city.

These organizations with respect to the scale of each city are ranked and have the appropriate essential functionality.

With no doubt, the contribution and influence of these organizations in mega-cities and the cities which are essential in national and international arena are maximal and yet important.

\section{Urban Planning}

Urban planning is involved in providing the citizens' welfare through more suitable, healthy, effective and desirable environ (Shie, 2003). Urban planning in the "Charter of Athens" is defined as: "Organizing a variety of spaces and environs which must provide and facilitated all the material and non-material, socio cultural dimensions and components in individual and social configurations" (Charter of Athens, 1976). The common pattern of urban planning is tabulated in Table (1). 
Table 1. the concepts and patterns of urban planning

\begin{tabular}{|c|c|c|c|c|c|}
\hline $\begin{array}{l}\text { The ideal } \\
\text { contribution of } \\
\text { state }\end{array}$ & $\begin{array}{l}\text { Local social } \\
\text { contribution }\end{array}$ & Proper approaches & $\begin{array}{l}\text { Cooperation } \\
\text { pattern }\end{array}$ & Local society & $\begin{array}{l}\text { Dimensions } \\
\text { Type of planning }\end{array}$ \\
\hline $\begin{array}{l}\text { Importance of } \\
\text { expertise and other } \\
\text { policies }\end{array}$ & $\begin{array}{l}\text { Cooperation in } \\
\text { scientific process }\end{array}$ & $\begin{array}{l}\text { Cost-benefit } \\
\text { Environmental } \\
\text { effects }\end{array}$ & $\begin{array}{l}\text { Consulting with } \\
\text { experts }\end{array}$ & $\begin{array}{l}\text { Generalization of the } \\
\text { interest through } \\
\text { experts }\end{array}$ & $\begin{array}{l}\text { Axiomatic or } \\
\text { comprehensive } \\
\text { technique }\end{array}$ \\
\hline $\begin{array}{l}\text { Balance } \\
\text { controversial } \\
\text { interests }\end{array}$ & $\begin{array}{l}\text { Cooperation based on } \\
\text { pluralism }\end{array}$ & $\begin{array}{l}\text { Research and } \\
\text { cooperation }\end{array}$ & $\begin{array}{l}\text { Selecting the } \\
\text { consumer }\end{array}$ & $\begin{array}{l}\text { Sub cultures' priority } \\
\text { and interests }\end{array}$ & $\begin{array}{l}\text { Step by step or free } \\
\text { will }\end{array}$ \\
\hline $\begin{array}{l}\text { Power and wealth } \\
\text { distribution }\end{array}$ & $\begin{array}{l}\text { Protesting plans } \\
\text { against sabotage }\end{array}$ & $\begin{array}{l}\text { Reinforcing } \\
\text { educational } \\
\text { procedures }\end{array}$ & $\begin{array}{l}\text { Announcing } \\
\text { opinions and } \\
\text { suggestions }\end{array}$ & $\begin{array}{l}\text { Sub cultures' } \\
\text { groupings }\end{array}$ & $\begin{array}{l}\text { Power of attorney or } \\
\text { supportive }\end{array}$ \\
\hline $\begin{array}{l}\text { Providing the basic } \\
\text { meet }\end{array}$ & $\begin{array}{l}\text { Self-authority and } \\
\text { self-independence }\end{array}$ & $\begin{array}{l}\text { Self-assistance and } \\
\text { will }\end{array}$ & Group designing & $\begin{array}{l}\text { Sociologic and } \\
\text { ecologic orders }\end{array}$ & $\begin{array}{l}\text { Gender oriented or } \\
\text { environmental }\end{array}$ \\
\hline $\begin{array}{l}\text { Power distribution } \\
\text { in local society }\end{array}$ & $\begin{array}{l}\text { Pluralism in decision } \\
\text { making process }\end{array}$ & $\begin{array}{l}\text { Ability of } \\
\text { simulating tools }\end{array}$ & Group designing & Public domain & Neighborhood units \\
\hline
\end{tabular}

(Birkland, 1992)

\section{The Physical Aspect of Urban Planning}

The physical planning of a region is concerned with issues like land use, communications, facilities, infrastructure, utilities etc. Physical planning is subject to the urban regulations and management which enables it to overpass the urban control and market mechanisms with respect to its advances (Hosseinzade, 2004).

- The non-physical of urban planning

The non-physical elements that constitute this aspect are the social, cultural and spiritual ones.

-Finding:

The importance and the essence of the non-physical structure in urban planning like culture, identity, religion, politics, competition, performance, social interaction, citizens' rights, social responsibility, participation, human behavior and the environ are the most essential elements. These elements, at any scale, space and time regardless of their type have been and are able to create a decisive and deep connection with their audience by revealing the physical and non-physical identity of the city through which the identification of the citizens is formed in order to organize mental structure of the citizens. In fact the main principle in urban planning is the necessity in identifying, protecting and giving priority to the non-physical structure in relation to the physical structure, if the objective is to build a Utopia. This is true, while being a "wishful thinking" since, unfortunately, at least in this era this doctrine is ignored due to the existing numerous physical-urban problems in "Urban planning" in general. In developing an analytic model, first the human needs, Table (1) should be identified and realized, and next the conceptual model of the urban social structure be provided, Fig. (2).

Identifying the dimensions of human substance has occupied the minds of the think-tanks and anthropologists who have been through many scientific challenges on this path.

Respecting the variety of the dimensions of human nature, where each one can be a source of different motivations and adopting them in coordinated structures which fulfill the human needs on individual and social sense is a feature of urban order (Saleh Nia et al, 2014).

Life substance and human survival is subject to needs, since life is a dynamic and self-subsist process, where human motivations make him face challenges in order to overcome them. These motivations are in the form of specific behaviors which represent the reflection towards the mentioned needs (Carver and Scheir, 1992).

In 1910 and 20s, since most of the geographers lacked the knowledge regarding the socio-economic organization, which are the constituent part of a city, they could not fit the socio-economic conditions into the urban morphology. In 1927, Bubackaddressed urban panorama caused by the innovation power of the urban society in a scientific manner and eventually in 1933, Valter Cristaler, in the urban geography in Germany, instead of emphasizing on form, chose the city functionality and paved the way for a new path in urban morphology. Accordingly it can be said that the new functionalities introduced in urban setting in its varieties is the outcome of socio-economic advances in the cities and this processes do introduce changes in the city form and systemize 
them (Shokooie, 2010).

The emphasis of urban planning value around the axiomatic elements: 1) Regionalization, 2) House building, 3) City roads network system, 4) Constructing public build up, 5) Green space, 6) Transportation facilities and 7) Parks, which constitute the physical planning elements. The physical urban planning must move in parallel with socio-economic planning if the objective is to meet all the aspects of an urban society in appropriate manner. Of course, a city cannot exist if the urban planning does not include the non-physical aspects with all its constituent elements as it's complementary.

The focus of non-physical aspect of urban planning on human factor where the objective is to achieve, a) social welfare, $b$ ) the environment cure, c) organize the citizens' participation, d) educate and e) promote ideology and struggle to upgrade the citizens' life style (Shokooie, 2010).

Urban planning as a hypothetic and empirical concept is in constant change and adapts itself to the modern ideas. The major evolutions in urban planning can be traced back in three periods: 1) from the late 19th century to mid 1960 s, industrialization and population growth where 1960s can be named the comprehensive period since in mid 60s a system was addressed upon which the second period evolved, 2) addressing the participation concept in 1970s and 3) the changes of urban planning occurred. Beginning 1980s the rapid orientation towards globalization and by beginning 1990s due to a reduction in public assets, weak economic and major crises left their influence on the new procedures in urban management (Daneshvar and Bandar Abad, 2013). In this article, based on what is said and the substantial dimensions of human as the physical and non-physical element, it is necessary to consider this double-dimensional concept when the issue is the human needs, since the city must keep both these elements satisfied.

\section{The Human Needs}

Needing is a fixed feature in human and mankind goes through many efforts and challenges to fulfill these needs and justify its existence and endurance. Some of these needs are these needs are non-material and yet essential for growth and welfare. Needs motivate, therefore cause adjustment in human conduct to be on the right path towards optimization (Marshal Rio, 2002). Life without need leads to gradual death. God created human with a built in desire, that is, this creature, in order to prosper through the evolutionary process, is doomed to make efforts in satisfying these needs. Necessity is the sole cause of materialization, but some do not consider this principle as sufficient and believe that mere need cannot motivate one since it is a kind of deficiency, while what can, is the sense of it. Accordingly, accepting the city as a living entity it can no longer be viewed by its physical dimensions. If the constituent affecting element of the non-physical dimension of the city is the human, the content and efficiency features through which the city is identified can be categorized in two:

1)The social (political and cultural) elements are known as the human-geography which include population (quantitative and qualitative) city culture or the citizens (race, language, art, clothing etc.); Therefore, in this dimension human is referred to as the axiom. Sciences, technologies, skills, thoughts and valuable and beneficial experiences learned from the past in the last analysis in this dimension are secondary to identify just like script, clothing, manufacturing methods, tradition and believes, ceremonies and alike known to us as national components, that is, the identity elements, the inevitable and 2) The economic elements, the last dimension involved in city identity with all the activities conducted in the past up to now by its citizens.

Some of these relevant activities, like tourism, handcraft or exhibition of cultural events unique to the space specific to a city or a geographical space are considered as the most important features of "identity" of that given entity. The objective of life is to reach bliss. Human of any principle or religion seeks better life. The two physical and non-physical dimensions of human existence are presented in a flowchart in Figure 1. 


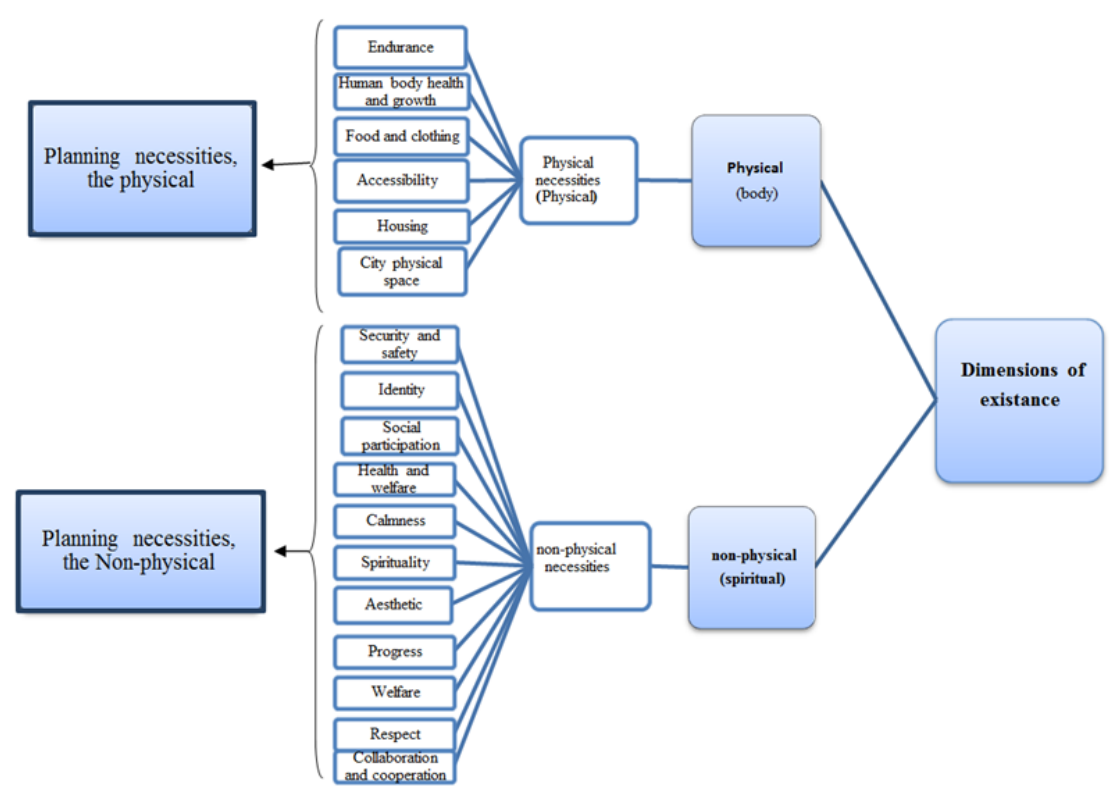

Figure 1. The physical and non-physical needs of human in urban planning

Source: the authors

Recognition of these two dimensions of human needs leads to proper planning specific to each one of the needs in order to satisfy them. The essence of non-physical needs in urban planning is preferred in this article. Lack of concern on the non-physical elements can lead to serious threat to the city identity. Proper improvements and major emphasis on these elements in parallel to the proper cooperation would result in a strong city structure.

\section{Focusing on Non-Physical Elements in Urban Planning is a Must}

Recognition of city organization is essential in urban planning order and the constituents of this organization are the physical and non-physical dimensions. It is obvious that in urban planning the non-physical dimension is the foundation of the physical dimension and if this sequence is not observed the disadvantages will overwhelm the advantages when the plan is executed. Unfortunately, what is observed now is unlike this obvious fact.

The mental view of a citizen is concerned with the sensual aspects perceived by him/her which is subject to occurrence in both the dimensions. Consequently, if cooperation and participation of the citizens regarding urban issues are expected, the proper spatial setup must correspond to human presence where he can develop sense of belonging and indirect possession.

Here, the physical aspect is influenced by the non-physical; the latter is the soul and the former is the body of the same entity, the city. The health and prosperity of every citizen is subject to efficiency and completeness of these two dimensions, Figure 2.

The physical dimension consists of pedestrian network, transportation, the city façade, different efficiencies etc.

The non-physical dimensions constitute the conceptual ground upon which the physical dimension is set. 


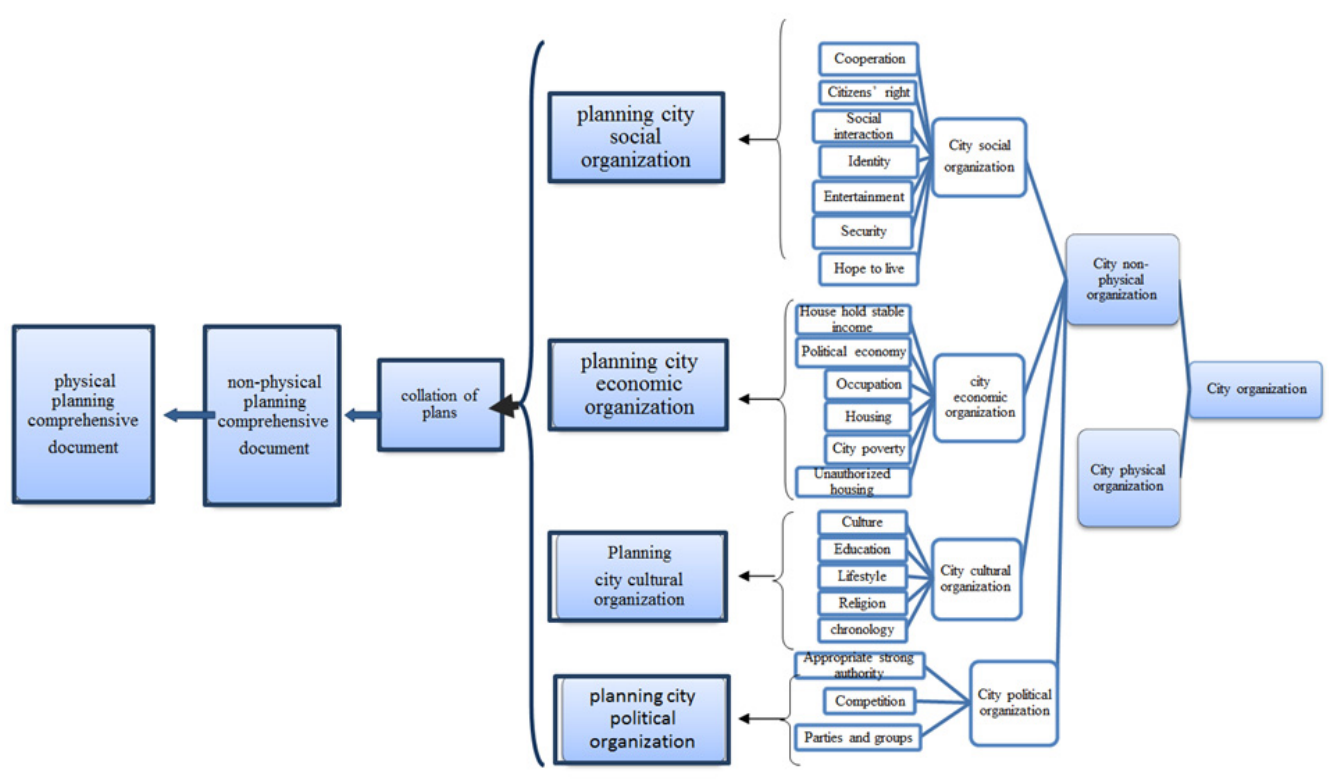

Figure 2. Planning of city organization

It should be mentioned that every organization has its own specific planning pattern; therefore, at a large scale we have city social, city economic, city cultural and city political organizations the coalition of which would yield the non-physical planning and physical planning comprehensive document.

In non-physical urban planning each one of the organizations must have their own independent plan. All the indicators Dos and Don'ts are deduced and applied in a qualitative manner.

\section{Conclusion}

Since city is a habitat, it should facilitate the appropriate atmosphere for human life. Designing a city is justified when its functionality and setup satisfy its inhabitants socio-physical needs. It is obvious that the range of human needs vary in accordance with their socio-economic status; hence the needs here, like anything else, are proportional. This proportionality is a built-in-phenomenon in all elements that constitute an urban setting, be it physical or non-physical. What is discussed in this article involves both the physical or non-physical dimensions of a city. In a preferential comparison of these dimensions prioritization of the non-physical dimension would yield more satisfaction on the citizens' part. Human consists of both these dimensions and when talking about human needs naturally both dimensions are involved. Accordingly, the city as a live entity must response to its citizens' needs with respect to both dimensions. Unfortunately, regarding urban planning the focus is mostly on the physical dimension; while in order to have a city worthy of full life, both dimensions should be of concern.

\section{References}

Aminzade, B., \& Mohammad, N. (2009). Islamic Utopia city of justice. Safeh Pub., Tehran, 12 $2^{\text {th }}, 20-31$.

Bently, I. et al. (2006). Responding environs. Trans. Mostafa Behzadfar, 2nd ed., Elmo Sanat University Pub., Tehran.

Birkland, J. (1992). Community Participation in urban Project Assessment an Ecofeminist Analysis. University Of Wollongony.

Carver. S. C., \& Scheir, M. F. (1992). Perspective on Personality. Allyn and Bacon.

Daneshvar, M., \& Bandar, A. A. (2013). Assessing the integration of national civic and development project according to strategic structural design (case study, the comprehensive civic and development project, city of mashhad). HoviateShahr Magazine, 7(14), 86-92.

Fakoohi, N. (2004). Urban anthropology. Nei pub., Tehran.

Hosseinzade, B. K. (2004). Regional planning. The study and development of textbooks of Social Sciences (samt), Tehran. 
Marshal, R. J. (2002). Motivation and excitement. Trans. Mohammadi. Virayesh Pub., Tehran.

Mesbah, Y. M. T. (1997). Ethics in the Quran, two The Cover, Imam Khomeini Education and Research Institute.

Mohamad, S. K. (1999). The format and the content of Islamic architecture. Fine Arts Pub., 12(1), 58-60.

Mohammad, I., \& Mohammad, K. K. (1992). Psychology of sense and comprehension. Samt Pub., Tehran.

Pakzad, J. (2006). Identity and becoming one with the space. Safeh Pub., Tehran, 100-107

Papoli, Y. H., \& Rajabi, S. H. (2008). Theories on city of Tehran and vicinity. Samt Pub., Tehran.

Saleh, N. et al. (2014). Social responsibility and sustainable development of urban Muslims, the first international conference on the political saga (with an emphasis Middle East) economic (with an emphasis on management and accounting).

Shi, I. (2003). Introduction to the principles of urban planning. University of Science and Technology, Tehran.

Shokoohi, H. (2010). A new outlook on urban geography. Humanitarian scientific Books Pub.

Torkashvand, A., \& Majidi, S. (2013). Reidentification of some symbols in city space. Urban Design Scientific Association of Iran Pub., 6, 5-15.

\section{Copyrights}

Copyright for this article is retained by the author(s), with first publication rights granted to the journal.

This is an open-access article distributed under the terms and conditions of the Creative Commons Attribution license (http://creativecommons.org/licenses/by/3.0/). 